\title{
Injuries to pedestrians in road traffic accidents
}

\author{
R M Atkins, W H Turner, R B Duthie, B R Wilde
}

Abstract

Although there have been many reports on injuries to occupants of cars in road traffic accidents, there have been few prospective studies of injuries to pedestrians in such accidents. For this reason a two year prospective study of pedestrians in road traffic accidents in the Oxford region was carried out.

The incidence of death in pedestrians was significantly higher than in car occupants or motorcyclists. The principal determinant of death was the weight of the vehicle concerned. The most common site of injury was the head because of a high incidence of brief concussion, but the most common site of serious injuries was the leg. Injuries to all regions of the body increased with age and with the weight of the vehicle in the collision. Accidents most often concerned young children or the elderly.

\section{Introduction}

Several studies have shown that a pedestrian in a road traffic accident is at great risk of being severely injured. ${ }^{1-6}$ Nevertheless, although there have been many reports on the injuries to the occupants of cars in such accidents, there have been few comprehensive, prospective studies of injuries to pedestrians. ${ }^{56}$ For this reason, as part of the investigations of the Oxford road accident group, we carried out a two year prospective study of injuries to pedestrians of all ages in the Oxford region.

\section{Methods}

We collected data during 1983 and 1984 on all pedestrians in road traffic accidents within the

\begin{abstract}
FIG 1-Distribution of age in pedestrians injured in road traffic accidents
\end{abstract}

Nuffield Department of Orthopaedic Surgery, Nuffield Orthopaedic Centre, Headington, Oxford OX3 7LD

R M Atkins, FRCs, lecturer W H Turner, BCH, senior house officer

R B Duthie, FRCS, professor

\section{Oxford Road Accident}

Group, Oxford

B R Wilde, BSC, research assistant

Correspondence to: Mr R M Atkins, Department of Orthopaedic Surgery, Bristol Royal Infirmary, Bristol BS2 8HW.

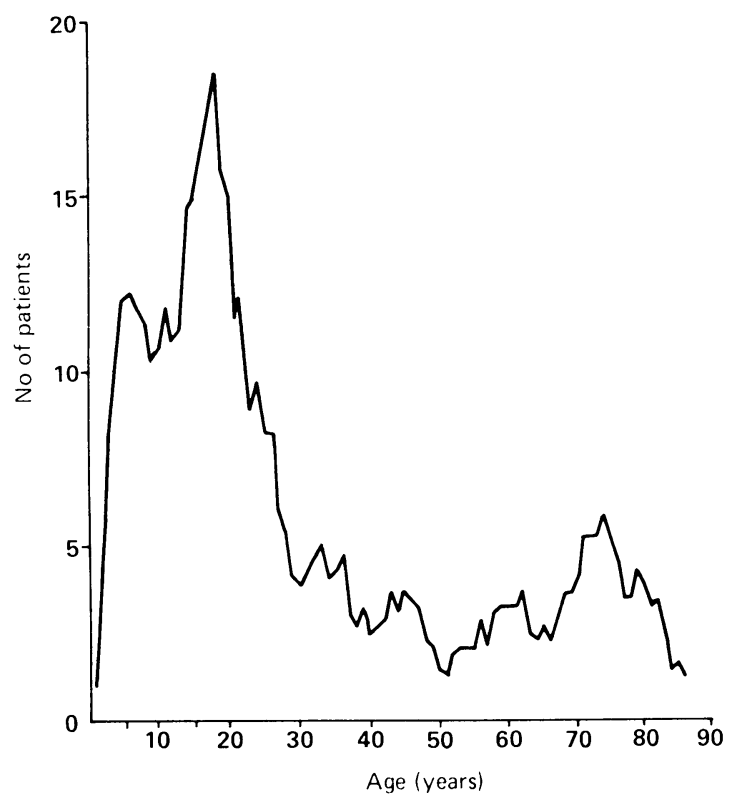

catchment area of the accident service of the John Radcliffe Hospital. This area serves a population of 370000 , of whom 89000 live within the city of Oxford. ${ }^{8}$ Data were obtained at the time of the accident about the circumstances of the accident and the vehicles concerned. The nature of the injuries was assessed, and the treatment received was documented. The information obtained about accidents to young people was analysed in more detail to document the risks to children as road users. Special attention was also paid to accidents in which there was a death, irrespective of the age of the victim. Consumption of alcohol was determined by questioning the patients and clinical examination. Blood alcohol concentrations were determined only in some fatal accidents where the information was clinically indicated.

The data for each accident were entered into a computer for further analysis and for comparison with accidents to other road users. Injuries were coded by type, severity, and region of the body affected according to the abbreviated injury score, ${ }^{9}$ and overall scores were coded for maximum abbreviated injury score. The significance of differences was estimated by $\chi^{2}$ analysis with Yates's correction if appropriate.

\section{Results}

Five hundred patients were available for review (299 male and 201 female). Their heights and weights were average for the population, and the age distribution was triphasic, showing a large peak at 15-20 years and small peaks at 5 years and 70-75 years. There were 40 children under 5 and 113 aged 5 to 15 (fig 1). The pattern of injury was broadly similar throughout the age groups, and the most common site of injury was the head $(33 \%)$ because of the high incidence of brief concussion. When only serious injuries were considered (abbreviated injury score $>2$ but excluding brief "knock outs") the leg was the most commonly injured region of the body, with a prevalence varying from $19 \%$ in people under 15 to $39 \%$ in those over 60 . The incidence of injury to all regions of the body increased with age with the exception of a slightly higher than predicted incidence of arm injuries in those aged 15-30.

When the 405 people with injured limbs were considered, in all age groups the right side was injured more often than the left and the leg more often than the arm (table I). Neither of these increases were statistically significant. There was no significant difference with age in the likelihood of injury to one side compared with the other or of injuries to the arm compared with the leg.

Most of the accidents concerned motorcars or taxis $(342,68 \%)$. Other vehicles were motorcycles (53, $11 \%)$, buses and coaches $(23,5 \%)$, pedal cycles $(23,5 \%)$, light goods vehicles $(19,4 \%)$, and heavy goods vehicles $(18,4 \%)$. The remaining 22 accidents concerned a variety of miscellaneous vehicles. Not surprisingly the incidence of injury to every region of 
the body increased with increasing weight of the vehicle, as did the severity of the injury. There were three broad patterns of injury. Firstly, accidents with pedal cycles produced predominantly trivial injuries and none with an abbreviated injury score greater than 3. Accidents with motorcycles, cars, and buses or coaches most commonly caused minor injuries, but there was an increased proportion of more severe injuries. Finally, collisions with goods vehicles produced almost the same number of injuries within each maximum abbreviated injury score.

When the injuries were more than trivial (abbreviated injury score $>2$ ) most patients were either admitted to hospital $(225,45 \%)$ or seen in the accident department $(216,43 \%)$ at a single visit. A further

TABLE I-Incidence of injuries to limbs according to side of body and age. Percentage values are injuries by side compared with the total number of injuries to that limb

\begin{tabular}{|c|c|c|c|c|c|c|c|c|}
\hline \multirow{2}{*}{$\begin{array}{c}\text { Age } \\
\text { (years) }\end{array}$} & \multicolumn{2}{|c|}{ Left arm } & \multicolumn{2}{|c|}{ Right arm } & \multicolumn{2}{|c|}{ Left leg } & \multicolumn{2}{|c|}{ Right leg } \\
\hline & No & $\%$ & No & $\%$ & No & $\%$ & No & $\%$ \\
\hline $0-5$ & 2 & 50 & 2 & 50 & 3 & 18 & 14 & 82 \\
\hline $6-15$ & 6 & 60 & 4 & 40 & 27 & 31 & 61 & 69 \\
\hline $16-65$ & 12 & 35 & 22 & 65 & 47 & 25 & 143 & 75 \\
\hline Over 65 & 4 & 27 & 11 & 73 & 7 & 15 & 40 & 85 \\
\hline
\end{tabular}

TABLE II -Numbers (percentages) of pedestrian casualties according to state of admission

\begin{tabular}{lr}
\hline \multicolumn{1}{c}{ State of admission } & No $(\%)$ \\
\hline Discharged and referred to own doctor & $216(43)$ \\
Referred to outpatient clinics & $48(10)$ \\
Admitted as inpatient & $225(45)$ \\
Died at scene or in ambulance & $10(2)$ \\
Left without being examined & $1(0)$ \\
\hline
\end{tabular}

TABLE III-Duration of stay in hospital of pedestrians admitted as inpatients

$\begin{array}{lllllllll}\text { No of nights in hospital } & 0 & 1 & 2 & 3-5 & 6-10 & 11-20 & 21-30>30 & \mathrm{NA}\end{array}$ \begin{tabular}{llllllllll}
\hline No of patients & $5^{\star}$ & 80 & 28 & 27 & 21 & 31 & 9 & 13 & $2 \dagger$
\end{tabular}

ॠThese patients died on the day of admission.

tThese patients were transferred to other hospitals.

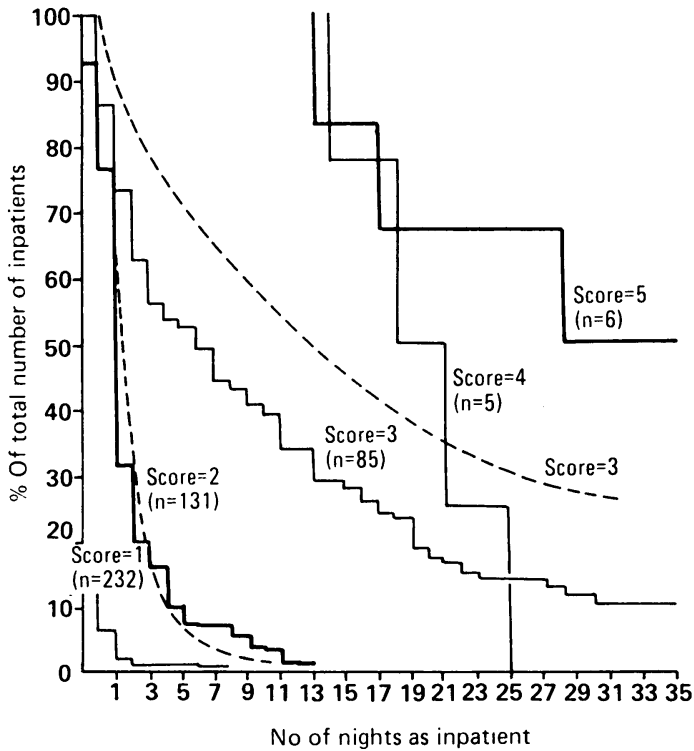

FIG 2-Duration of hospital stay for pedestrians with different maximum abbreviated injury scores. Dashed lines represent the data of Hobbs et al. ${ }^{10}$ Results are expressed as a percentage of the total number of pedestrians admitted to hospital with that score

$48(10 \%)$ patients were referred from the accident department to a clinic, and 10 people (2\%) died at the scene of the accident. One patient discharged himself from the accident department without being seen (table II). Of those patients admitted to hospital, $80(37 \%)$ remained for only one night and a further 55 (26\%) for less than a week. Twenty four patients were in hospital for more than 20 nights and 11 were still in hospital at the time of review (table III). The length of stay in hospital increased with the maximum abbreviated injury score (fig 2). Within each score the elderly had the longest stays in hospital; for those with a maximum abbreviated injury score of 3 the median stay was 16 nights for the over $65 \mathrm{~s}$, six nights for those aged 15-65, and three nights for those aged 6-15.

\section{FATAL ACCIDENTS}

There were 27 deaths, 15 of which occurred at the scene of the accident or on the first day of admission to

TABLE IV-Details of 27 pedestrians who died as a result of a road traffic accident

\begin{tabular}{|c|c|c|c|c|c|c|c|c|c|c|}
\hline $\begin{array}{l}\text { Case } \\
\text { No }\end{array}$ & Age & Sex & Vehicle & $\begin{array}{l}\text { Time of } \\
\text { accident }\end{array}$ & $\begin{array}{l}\text { Interval to } \\
\text { death }\end{array}$ & Alcohol & $\begin{array}{c}\text { Site of } \\
\text { accident }\end{array}$ & $\begin{array}{l}\text { Primary cause of } \\
\text { death }\end{array}$ & Associated causes & Comment \\
\hline 1 & 54 & $M$ & Car & 2330 & 4 months & NA & City & Bronchopneumonia & Cerebral contusion & \\
\hline 2 & 52 & $M$ & Lorry & 1017 & 9 days & NA & Open road & Severe chest injury & Cerebral contusion & \\
\hline 3 & 70 & $\mathrm{~F}$ & Car & 1139 & 13 days & NA & City & Pulmonary and renal failure & Cerebral contusion & On zebra crossing \\
\hline 4 & 78 & M & Fire engine & 1649 & 14 days & NA & City & Bronchopneumonia & Severe chest injury & \\
\hline 5 & 41 & $M$ & Car & 2250 & 10 days & NA & City & Bronchopneumonia & Pelvic fracture and splenic rupture & \\
\hline 6 & 75 & $\mathbf{F}$ & Bus & 1115 & $1 / 2$ hour & NA & City & Rupture of the aorta & Severe chest and head injury & \\
\hline 7 & 72 & $M$ & Lorry & 1625 & Died at scene of accident & None & City & Cerebral contusion & Multiple fractures & \\
\hline 8 & 16 & $M$ & Lorry & 0745 & Died at scene of accident & None & Open road & Cerebral contusion & Multiple fractures & \\
\hline 9 & 58 & $M$ & Car & 1410 & Died at scene of accident & None & Dual carriageway & $\begin{array}{l}\text { Severe injuries of the head, } \\
\text { spine, and aorta }\end{array}$ & & \\
\hline 10 & 39 & $\mathbf{M}$ & Car & 2030 & Died in casualty & $1 \cdot 2 \mathrm{~g} / \mathrm{l}$ & Open road & Cerebral contusion & $\begin{array}{l}\text { Multiple fractures and internal } \\
\text { injuries }\end{array}$ & \\
\hline 11 & 80 & $\mathbf{M}$ & Motorcycle & 1408 & 2 weeks & NA & Open road & Bronchopneumonia & Cerebral injury & \\
\hline 12 & 76 & $M$ & Van & 0741 & 1 month & NA & Woodstock & Cerebral injury & Multiple fractures & Always confused \\
\hline 13 & 30 & $M$ & Coach & 2245 & Died in casualty & None & Open road & Ruptured lungs & Multiple fractures & \\
\hline 14 & 27 & $\mathbf{F}$ & Car & 0750 & Died in casualty & $\mathrm{NA}$ & Open road & Severe brain injury & & \\
\hline 15 & 81 & $\mathrm{~F}$ & Van & 1244 & 14 days & NA & Kidlington & Severe lung injury & Cerebral contusion & Blind \\
\hline 16 & 17 & $\mathbf{F}$ & Car & 0548 & Died at scene of accident & None & Open road & Cerebral contusion & & \\
\hline 17 & 17 & $M$ & Car & 2030 & Died at scene of accident & $5 \cdot 3 \mathrm{~g} / 1$ & Dual carriageway & Severe cerebral injury & & \\
\hline 18 & 32 & $\mathbf{F}$ & Car & 1515 & 5 days & $\mathrm{NA}$ & Open road & Severe cerebral injury & & \\
\hline 19 & 50 & $\mathbf{M}$ & Car & 1940 & Died at scene of accident & NA & Open road & $\begin{array}{l}\text { Transected spinal cord and } \mathrm{Cl} \\
\text { dislocation }\end{array}$ & Multiple injuries & \\
\hline 20 & 3 & $\mathbf{M}$ & Van & 0950 & Died at scene of accident & NA & Open road & Cerebral injury & Severe injury to chest and legs & \\
\hline 21 & 60 & $\mathrm{~F}$ & Car & 1140 & 2 days & NA & Wantage & Cerebral injury & & \\
\hline 22 & 46 & $\mathbf{M}$ & Lorry & 1030 & Died same day & NA & Open road & Cerebral injury & & Suicide \\
\hline 23 & 5 & $\mathrm{~F}$ & Car & 1700 & Died same day & NA & City & Cerebral injury & Multiple injuries & \\
\hline 24 & 81 & $M$ & Bus & 1540 & 4 days & $\mathrm{NA}$ & City & Cerebral injury & Multiple fractures & \\
\hline 25 & 77 & $\mathbf{M}$ & Motorcycle & 1705 & Died at scene of accident & NA & Abingdon & $\begin{array}{l}\text { Fracture-dislocation of cervical } \\
\text { spine }\end{array}$ & & \\
\hline 26 & 81 & $M$ & Car & 1005 & 2 days & NA & Open road & Bronchopneumonia & & \\
\hline 27 & 71 & $M$ & Motorcycle & 2229 & Died at scene of accident & $1.29 \mathrm{~g} / \mathrm{l}$ & Open road & Ruptured aorta and heart & Multiple internal injuries & \\
\hline
\end{tabular}


hospital (table IV). This gives an overall incidence of death of $5 \%$ for pedestrians, which was significantly higher than for occupants of cars $(64 / 2211$ cases, $3 \%$, $\mathrm{p}<0.02)$ and motorcyclists $(31 / 1498$ cases, $2 \%$, $\mathrm{p}<0.001$ ) in the Oxford road accident group study. There was a broad spread of ages in patients who had fatal accidents, and, while most of these concerned motorcars (table V), when these figures were adjusted for the number of accidents due to each type of vehicle death was most probable after being hit by a goods vehicle $(8 / 37$ cases, $22 \%$ ), followed by buses and coaches, cars, and motorcycles. No deaths occurred to pedestrians in accidents with pedal cyclists. Eleven of the 27 deaths were in people over 65 .

In 14 cases the cause of death was a severe head injury, and in 11 death was due to cardiothoracic injuries, two of which were ruptures of the aorta. In the

TABLE V-Details of vehicles concerned in fatal accidents

\begin{tabular}{lcc}
\hline $\begin{array}{c}\text { Type of vehicle } \\
\text { concerned }\end{array}$ & No $(\%)$ of accidents & $\begin{array}{c}\text { No }(\%) \text { of accidents that } \\
\text { were fatal }\end{array}$ \\
\hline Car & $342(68 \cdot 4)$ & $13(4)$ \\
Motorcycle & $53(10 \cdot 6)$ & $3(6)$ \\
Bus or coach & $23(4 \cdot 6)$ & $3(13)$ \\
Pedal cycle & $23(4 \cdot 6)$ & $0(0)$ \\
Goods vehicle & $37(7 \cdot 4)$ & $8(22)$ \\
\hline
\end{tabular}

remaining two cases the spinal cord was transected in the cervical region. One case was a suicide in a 46 year old man, one person who died was demented, and a third person an elderly woman, was blind.

TEMPORAL DISTRIBUTION OF ACCIDENTS

The monthly presentations of pedestrians who were injured in road traffic accidents, when compared for both 1983 and 1984, did not vary systematically, although May showed a slightly lower incidence in both years. The day of presentation averaged over the whole period varied from a minimum of 54 cases on Tuesdays to a maximum of 89 cases on Thursdays. There was, however, no pronounced increase on particular days and the variation was not the same in the two years.

The time of the accident was known in $95 \%$ of the cases, and in the remaining $5 \%$ it was assumed to have occurred in the hour before hospital attendance. Accidents most commonly occurred between 8 am and $9 \mathrm{am}, 4 \mathrm{pm}$ and $6 \mathrm{pm}$, and $11 \mathrm{pm}$ and midnight. The peak late at night was most pronounced in those aged 15-30, whereas the peaks in the morning and early evening consisted mostly of the youngest patients. Accidents to patients over 65 were evenly spread between 10 am and $7 \mathrm{pm}$.

\section{USE OF ALCOHOL}

The use of alcohol by pedestrians was confirmed by direct questioning where possible (111 cases), or by mention in the notes of clinical evidence of consumption, or by findings at necropsy (table VI); 29 $(16 \%)$ of the patients aged 15 to $30,14(15 \%)$ of those aged 31 to 60 , and only four (4\%) of those aged over 60 admitted to drinking alcohol. Overall, 47 (9\%) gave a positive answer but use of alcohol was not known in $205(41 \%)$ of the patients.

TABLE VI-Use of alcohol in 500 pedestrians in road traffic accidents. Figures are numbers (percentages) of pedestrians

\begin{tabular}{lccccc}
\hline \multicolumn{5}{c}{ Age (years) } & \\
\cline { 2 - 5 } \multicolumn{1}{c}{ Use } & $0-14$ & $15-30$ & $31-60$ & $>60$ & \multirow{2}{*}{ Total } \\
\hline Yes & $0(0)$ & $29(16)$ & $14(15)$ & $4(4)$ & $47(9)$ \\
No & $98(71)$ & $63(35)$ & $32(35)$ & $55(61)$ & $248(50)$ \\
Not known & $41(30)$ & $87(49)$ & $46(50)$ & $31(34)$ & $205(41)$ \\
\hline
\end{tabular}

\section{ROAD CONDITIONS}

Most of the accidents occurred in built up areas $(340,68 \%)$ and on single carriageway roads with speed limits of $30 \mathrm{mph}(48 \mathrm{kph})(327,64 \%)$. Details of the weather conditions and road surface at the time of the accident were not always known, but most accidents occurred during daylight ( $76 \%, 346 / 457$ known cases), on dry roads $(86 \%, 188 / 218)$, and in fine weather $(93 \%$, 231/249).

\section{ACCIDENTS TO YOUNG PEDESTRIANS} Children of 0-5 years

Of the 40 children in this group there were 14 aged 5, 13 aged 4, and seven, five, and one aged 3,2, and 1 respectively. Nineteen of them were discharged from hospital after one visit and 18 were admitted. There were two deaths in this group. All of the children who were discharged had minor external injuries only, seven of those who were admitted had mild head injuries and remained for only one night, and two were admitted with greenstick fractures of the tibia and fibula. Longer admissions were for fractures of the occiput, open fractures of the tibia and fibula, serious leg lacerations, fracture of the femur, and more serious head injuries.

All of the accidents occurred between 8 am and $8 \mathrm{pm}$. There was no systematic variation of the incidence with day of the week, and variation by month was irregular with eight accidents (20\%) occurring in August and only one each in December and January. Sixteen accidents occurred in the street where the child lived and nine more occurred within half a mile $(800 \mathrm{~m})$ of the child's home. In three cases the location of the accident was not recorded, and in the remaining 12 the accident was further from the child's home. The typical history was that the child ran into the road and was hit ( 12 cases). Two children were hit by vehicles using private entrances and two were hit while at the side of the road. Nine children were recorded as being with adults at the time of the accident (two of the children were in pushchairs), but the presence or absence of an adult was not usually recorded. Of these nine children, one was hit on a pelican crossing by a driver who had not seen the red light; one was hit by her father's own car while he was manoeuvring in a narrow lane; one child in a pushchair was pushed out into the traffic by an au pair who had looked the wrong way and was also hit; two were hit on the pavement or roadside; one was called across the road by his mother; and the rest disobeyed or ignored the adults' instructions.

\section{Children of 6-15 years}

Forty eight (42\%) of these patients were discharged after a single hospital visit and the remainder were admitted. There were no deaths in this age group. Accidents occurred most often between 8 am and 9 am $(19,17 \%), 3 \mathrm{pm}$ and $4 \mathrm{pm}(22,19 \%)$, and in the early evening between $4 \mathrm{pm}$ and $7 \mathrm{pm}(42,37 \%)$. The most common day for accidents was Friday, and accidents occurred slightly less often at the weekend. There was no systematic variation with month of the year and there was no reduction in incidence in the holiday month of August. Most of the accidents occurred in built up areas (80, 95\% of known cases), on unclassified roads $(57,56 \%)$, and during daylight hours $(98,87 \%)$.

\section{Discussion}

The results show an increase in severity of injuries suffered by pedestrians with increasing weight of the vehicle concerned. The disproportionately high incidence of brief "knock outs" seen after the pedal cycle and motorcycle accidents is probably accounted for by the head striking the ground after the casualty 
had been knocked over. Most of the other injuries were caused by direct contact with the vehicle, accounting for the increased incidence of injury to the higher regions of the body when struck by a large vehicle. To attempt to draw detailed conclusions on the probabilities of types of injury from these data would, however, be inappropriate because of the overwhelming prevalence of accidents concerning cars. The high proportion of accidents with cars accounts for the observation that most of the deaths were due to such accidents. In fact, the weight of the vehicle was the best determinant of whether an accident would result in death.

Other investigators have implicated intoxication with alcohol as an important factor in pedestrian road traffic accidents. ${ }^{7}$ The apparent absence of this in our studies may reflect a different pattern of alcohol use in the Oxford area or it may be the result of the inexact and incomplete methods that we used to assess alcohol consumption. We did not find a large peak in injuries to pedestrians on Friday or Saturday night as reported by Galloway and Patel. ${ }^{7}$ There was, however, a peak in the late evening each day for those aged 16-65, and this may have been related to use of alcohol. More detailed studies on the influence of alcohol in road traffic accidents in the Oxford region are now in progress.

The time of accidents in the 5-16 age group suggests a strong relation with journeys to and from school. On the other hand, the large number of accidents in August, during the school holidays, suggests that school journeys were not abnormally hazardous compared with other journeys. In children aged $0-5$ many of the accidents appear to have been due largely to inadequate adult care.
Hobbs et al analysed the length of hospital stay for 523 pedestrians who had been injured in a road traffic accident in 1974-6 (fig 2). ${ }^{10}$ The median hospital stay for a maximum abbreviated injury scale of 1 or 2 was similar to that in our study. For a score of 3, however, the median stay was seven days in our study while in their study it was 13 days. This suggests that more zealous modern management may shorten the hospital stay for serious but not overwhelming injuries.

We conclude that a pedestrian in a road traffic accident has a higher risk of dying than the occupant of a car or a motorcyclist and is more likely to be admitted to hospital than the occupant of a car. We suggest that ways of reducing the mortality of pedestrians in road traffic accidents should be investigated.

1 Galloway DJ, Patel AR. Road traffic accident related morbidity as seen in an accident and emergency department. Scott Med f 1981;26:121-4

Richter ED. Death and injury from motor vehicle crashes in Israel: epidemiology, prevention and control. In $\mathcal{f}$ of Epidemiol 1981;10:145-53.

Tanz RR, Christoffel KK. Pedestrian injury. The next motor vehicle iniury challenge. Am f Dis Child 1985:39:1187-90.

4 Illingworth CN. 227 Road accidents to children. Acta Paediatr Scand 1979;68: 869-73.

5 Illingworth CN, Noble D, Bell D, Kenn I, Roche C, Pasco J. 150 Bicycle injuries in children. A comparison of accidents due to other causes. Injury 1981:13:7-9.

6 Tunbridge RJ, Everest JT, Wild BA, Johnstone RA. An indepth study of road accident casualies and their injury patterns. Crowthorne: Transport and Road Research Laboratory, 1988. (TRRL Laboratory Report 136.)

7 Galloway DJ, Patel AR. The pedestrian problem: a 12 month review of pedestrian accidents. Injury 1982;13:294-8.

8 Oxfordshire County Council Research and Intelligence Unit. Population and household forecasts for Oxfordshire wards and parishes. Oxford: Oxfordshire County Council, 1985.

9 American Association for Automotive Medicine. The abbreviated injury scale. Moreton Grove, Illinois: AAAM, 1980

10 Hobbs CA, Gratton E, Hobbs JA. Classification of injury severity by length of stay in hospital. Crowthorne: Transport and Road Research Laboratory, 1979. (TRRL Laboratory Report 871.)

Accepted 26 September 1988)
Netherlands Centre for Monitoring of Adverse Reactions to Drugs, PO Box 5406, 2280 HK Rijswijk, The Netherlands B H Ch Stricker, PHD, medical officer

Diaconessenhuis,

Voorburg, The

Netherlands

G Slagboom, MD, physician

St Elisabeth Ziekenhuis, Aalst, Belgium

R Demaeseneer, MD, physician

Genk, Belgium

V Slootmaekers, MD, general practitioner

Centre National de

Pharmacovigilance,

Brussels, Belgium

I Thijs, PHARMD,

pharmaceutical officer

World Health Organisation

Collaborating Centre for

International Drug

Monitoring, Uppsala,

Sweden

S Olsson, PHARMD,

pharmaceutical officer

Correspondence to:

Dr Stricker.

\section{Anaphylactic reactions to cinoxacin}

\section{B H Ch Stricker, G Slagboom, R Demaeseneer, V Slootmaekers, I Thijs, S Olsson}

\begin{abstract}
During 1981 to mid-1988 three cases of anaphylactic shock after treatment with the quinolone derivative cinoxacin were reviewed by the Netherlands Centre for Monitoring of Adverse Reactions to Drugs and 17 cases of an anaphylactic type of reaction notified to the World Health Organisation Collaborating Centre for International Drug Monitoring. In five out of six patients for whom data were available the reaction began shortly after taking a single capsule of a second or next course of treatment. Cinoxacin is related to nalidixic acid, and one patient previously treated with that agent subsequently had an anaphylactoid reaction to cinoxacin and later developed a skin reaction to nalidixic acid. There were no deaths, and patients treated as an emergency with plasma expanders or with adrenaline and corticosteroids generally recovered promptly and uneventfully.
\end{abstract}

In view of the potentially fatal consequences of anaphylactic reactions to cinoxacin and other quinolones doctors should take care when prescribing these drugs.

\section{Introduction}

Cinoxacin is a chemotherapeutic agent which is used in the treatment of urinary tract infections. The drug is a quinolone derivative related to nalidixic acid. Adverse reactions to nalidixic acid are usually toxic rather than allergic. ${ }^{1}$ In the case of cinoxacin allergic reactions have been recorded. ${ }^{2}$ The data sheet in most countries mentions mild anaphylactoid reactions such as urticaria and angio-oedema but so far as we know not anaphylactic shock; and we are not aware of any instance of anaphylactic shock having been reported in the medical press. We therefore describe three patients who suffered this potentially fatal adverse reaction and present further data on anaphylactic and anaphylactoid reactions from the World Health Organisation's programme for international drug monitoring and from the Food and Drug Administration of the United States.

\section{Details of cases}

\section{CASES REVIEWED BY NETHERLANDS CENTRE}

Case 1-In 1983 a 27 year old woman received a course of cinoxacin for cystitis. In May 1984 she again presented with dysuria. Ten minutes after taking one capsule of $500 \mathrm{mg}$ cinoxacin she complained of paraesthesia in the hands and feet, which rapidly became generalised. Concomitantly pruritus, dyspnoea, and generalised erythematous rash occurred. On admission to hospital 20 minutes later her blood pressure was $70 / 50 \mathrm{~mm} \mathrm{Hg}$. She denied using any other drugs. She quickly recovered after treatment with adrenaline and corticosteroids.

Case 2-In October 1986 a 69 year old woman took six capsules of $500 \mathrm{mg}$ cinoxacin. On 21 November because of dysuria she decided to complete the course and took one of the remaining capsules. Ten minutes 